\title{
Can Coyotes Affect Deer Populations in Southeastern North America?
}

\author{
JOHN C. KILGO, ${ }^{1}$ United States Department of Agriculture Forest Service Southern Research Station, P.O. Box 700, Nerw Ellenton, SC 29809, USA \\ H. SCOTT RAY, United States Department of Agriculture Forest Service-Savannah River, P.O. Box 700, Nerw Ellenton, SC 29809, USA \\ CHARLES RUTH, South Carolina Department of Natural Resources, P.O. Box 167, Columbia, SC 29202, USA \\ KARL V. MILLER, Daniel B. Warnell School of Forestry and Natural Resources, University of Georgia, Athens, GA 30602, USA
}

\begin{abstract}
The coyote (Canis latrans) is a recent addition to the fauna of eastern North America, and in many areas coyote populations have been established for only a decade or two. Although coyotes are known predators of white-tailed deer (Odocoileus virginianus) in their historic range, effects this new predator may have on eastern deer populations have received little attention. We speculated that in the southeastern United States, coyotes may be affecting deer recruitment, and we present 5 lines of evidence that suggest this possibility. First, the statewide deer population in South Carolina has declined coincident with the establishment and increase in the coyote population. Second, data sets from the Savannah River Site (SRS) in South Carolina indicate a new mortality source affecting the deer population concurrent with the increase in coyotes. Third, an index of deer recruitment at SRS declined during the period of increase in coyotes. Fourth, food habits data from SRS indicate that fawns are an important food item for coyotes during summer. Finally, recent research from Alabama documented significant coyote predation on fawns there. Although this evidence does not establish cause and effect between coyotes and observed declines in deer recruitment, we argue that additional research should proactively address this topic in the region. We identified several important questions on the nature of the deer-coyote relationship in the East.
\end{abstract}

KEY WORDS Canis latrans, coyote, fawn, Odocoileus virginianus, predation, Savannah River Site, South Carolina, white-tailed deer.

During the last half of the 20th century, the range of the coyote (Canis latrans) expanded dramatically. Although a few isolated records indicate that coyote-like canids periodically occurred in the East during the late Pleistocene, coyotes were restricted to western North America at the time of European settlement and apparently had been since the Pleistocene (Nowak 1978). Coyotes now occupy most of North and Central America (Nowak 1978, Gompper 2002). Eastward of the historic western range, coyotes now occur throughout eastern North America from New Brunswick, Canada, to Florida, USA. Range expansion through the Midwest into the Northeast is believed to have been unaided directly by man, but was facilitated by the clearing of forests and by extirpation of other predators that once suppressed coyotes (Gompper 2002). However, expansion into the southeastern United States likely resulted from direct translocation and subsequent release (both accidental and intentional) of coyotes by humans (Hill et al. 1987). Habitat change and loss of predators, particularly the native red wolf (C. rufus), may have facilitated establishment of coyotes in the Southeast, but coyotes are not native to the region and are there now as a result of anthropogenic activity.

Although the coyote has been established in some parts of the Southeast for several decades, many areas, particularly along the South Atlantic coast, have been colonized quite recently (Main et al. 2000, Houben 2004). Coyote populations have grown rapidly and coyotes are now abundant in areas where they did not occur 20-30 years ago. In South Carolina, the first record of a coyote was in 1978 but by the mid-1990s coyotes occupied the entire state (Ruth 2008). Few long-term data sets exist on coyote population trends in the region, and harvest by trappers is often the only index available (Lovell et al. 1998). Trapping

\section{${ }^{1}$ E-mail: jkilgo@fs.fed.us}

harvest for South Carolina reflects the increasing population trend during the 1990s (Fig. 1). The sharp increase in the number of coyotes harvested after 2003 likely resulted from a legislative change that legalized the sale of live coyotes within the state. However, the spike in the trend is corroborated by the estimated number of coyotes incidentally shot by deer hunters in those years. Although the number of coyotes shot is subject to bias as well and the actual slope of the curve is unknown, it is clear that coyotes have increased in the state since the mid1980s and that most of that growth has occurred since the mid1990s. Other southeastern states have experienced similar trends, if in slightly different timeframes (Lovell et al. 1998).

Ample evidence exists in the literature demonstrating that coyote predation on white-tailed deer (Odocoileus virginianus), particularly neonatal fawns, can be high (e.g., Cook et al. 1971, Bartush and Lewis 1981, Whittaker and Lindzey 1999, Vreeland et al. 2004). After reviewing this literature, Ballard et al. (2001) concluded that coyotes can be a significant mortality factor for deer, and Ballard et al. (1999) suggested that coyotes have replaced wolves in their role as deer predators in parts of northeastern North America, frequently taking adults during winter as well as neonatal fawns. Although in some situations coyote predation on fawns is compensatory to other mortality factors (Bartmann et al. 1992, Bishop et al. 2009), it also has been shown to be additive, and therefore limiting, in other situations (Messier et al. 1986, Patterson et al. 2002). Notably, most research related to coyote impacts on deer has been conducted either in the historic range of the coyote or in northeastern North America where winter severity contributes to susceptibility to predation (Gompper 2002). No direct assessments of coyote impacts have been conducted in the forested landscapes and mild climate of the Southeast and midAtlantic regions, although a recent study examined coyote 


\section{DE- AI09-00SR22188}

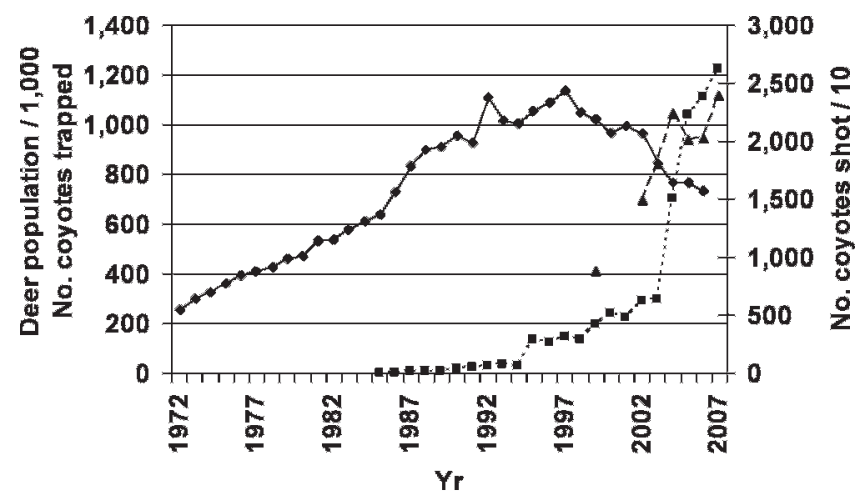

- Deer $\cdots \cdots$ Coyotes trapped $-₫-$ Coyotes shot

Figure 1. Estimated statewide deer population size (1972-2006), coyote trapping harvest (1986-2007), and estimated number of coyotes shot by deer hunters $(1999,2002-2007)$ in South Carolina, USA (C. Ruth, South Carolina Department of Natural Resources, unpublished data).

predation on deer in a suburban setting in Alabama (Saalfeld and Ditchkoff 2007). Whether potential regional variation in coyote body size, packing behavior, or any other factor will affect the nature of predation and its relative impact in the Southeast is unknown.

Despite establishment of coyotes in the region and evidence from other regions that coyotes can impact deer populations, concern among wildlife professionals about potential effects has been limited. It is unclear whether this lack of concern stems from a perception that coyotes are not significant predators of deer in the region or from the belief that deer populations are high enough to sustain predation. Indeed, an additional mortality source may have been welcomed in areas of deer overpopulation. Because of the mild climate of the region, mortality from winter nutritional stress is minimal, and hunter harvest is believed to drive the dynamics of most populations. Whatever the cause, the issue has received little attention. To illustrate, we searched abstracts of the annual meeting of the Southeast Deer Study Group from its inception in 1977 through 2005 for any mention of coyotes. Among nearly 1,000 abstracts, coyotes were mentioned in only 10, and of those, most studies were conducted within the coyote's historic range (TX, OK, $\mathrm{MO}$ ). Only two, both in Alabama, were conducted in recently occupied areas.

Clearly, the potential for predation by coyotes to impact deer populations in an area outside the coyote's historic range is an issue that warrants further attention. The landscape, vegetation, and fauna of the region differs from the coyote's historic range, so their behavior and food habits may likewise differ, especially considering their behavioral and dietary flexibility (Hilton 1978). We present unpublished long-term data from South Carolina and cite recent research from Alabama that we feel collectively suggest that coyotes may influence deer populations in the region. We acknowledge these data do not prove a cause-and-effect relationship but, taken together, we feel that they are suggestive of such a relationship and warrant further research attention.

\section{SOUTH CAROLINA DEER TRENDS}

\section{Statewide Trend}

The estimated statewide deer population in South Carolina declined by 36\% between 1997 and 2006 (Fig. 1; Ruth 2008). As in other eastern states, following the restoration programs of the 1950s and 1960s, the deer population climbed quickly during the 1970s and 1980s. It peaked at approximately 1.1 million between 1992 and 1997 and then began a decline that has continued through the present to approximately 750,000 .

Clearly, many factors may play a role in the recent decline. For example, large-scale habitat changes associated with forest management occurred during the period of decline. Extensive establishment of pine plantations throughout the state during the 1980s resulted in a landscape with a greater proportion of 15-30-year-old pine forest, which provides limited forage for deer (Ruth 2008). In addition, extensive land development in the Piedmont and coastal regions of the state has reduced the acreage of habitat available. However, the decline in the deer population also closely tracks the growth of the coyote population (Fig. 1). The indices used for both populations are subject to numerous biases and, because of the extensive scale in space and time, may oversimplify any possible relationship. Nevertheless, the timing of the decline in deer numbers is highly coincidental with the increase in coyote abundance.

\section{Savannah River Site Deer Population History}

Long-term site-specific data may be less susceptible to biases associated with statewide data. The Savannah River Site (SRS) is a 78,000-ha tract in western South Carolina, situated in the Upper Coastal Plain physiographic region. The landscape of the SRS is dominated by pine forest, and although forest rotation lengths are longer than average for the area, the site is generally representative of habitat in the region. With recovery of the deer population in the 1960s, hunting was initiated in 1965 . Driving deer with hounds was the primary hunting method from 1965 to the present (but still hunts were conducted on a limited portion of the area from 1969 to 1981). The primary objective of hunts was to control the deer population to limit the number of deervehicle accidents. Therefore, hunts were either sex, usually with no bag limit, and hunters were encouraged to harvest any deer, regardless of age or sex. As a result, the sex ratio of both the harvest and the population was approximately even and density was low (4-8 deer $/ \mathrm{km}^{2}$; Johns and Kilgo 2005).

Novak et al. (1991) used harvest data to develop a stochastic, catch-effort, competing risks population model for the SRS deer population. For the period analyzed (1965-1986), Novak et al. (1991) concluded that harvest was the primary mortality source in the population. Novak et al. (1991) estimated nonhunting mortality equivalent to a $26 \%$ annual mortality rate across all sex and age classes. The relationship between harvest and population size at SRS apparently persisted through the early to mid-1990s, a span of approximately 30 years, as the 2 variables tracked each other closely (Fig. 2). 


\section{DE- AI09-00SR22188 Journal Article $2010 \quad$ 10-08-P}

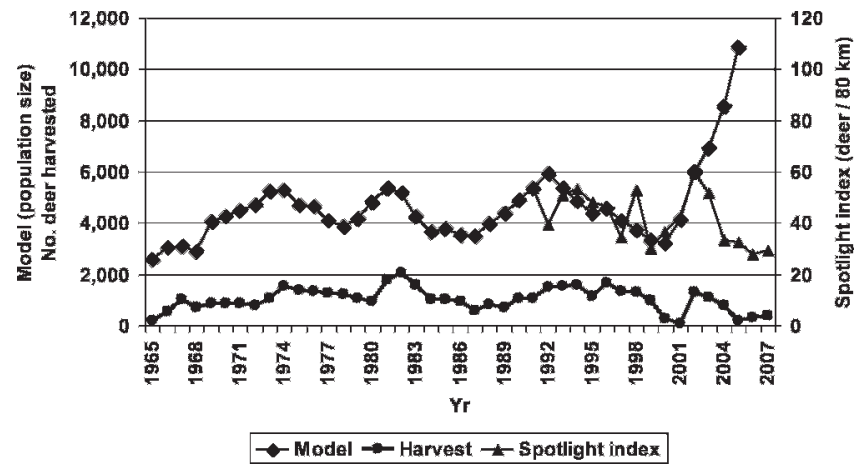

Figure 2. Estimated prehunt deer population size from population model, 1965-2005 (1965-1986 from Novak et al. 1991; 1987-2003 from Johns and Kilgo 2005; 2004-2005 from J. Novak, Eastern Illinois University, unpublished data), index of deer population size from February spotlight survey, 1991-2007 (H. S. Ray, United States Department of Agriculture Forest Service, unpublished data), and deer harvest, 1965-2007 (H. S. Ray, unpublished data) on the Savannah River Site, South Carolina, USA.

Examination of the trends after 2000 indicate that harvest is no longer the only significant mortality source. In response to a downward trend in the population from 1992 to 2000 (Fig. 2), female harvest was suspended in 2000. Total harvest declined by more than the expected $50 \%$, perhaps because hunters were forced to pass on some shots to confirm sex of the deer. Following the events of 11 September 2001, hunts that year were cancelled due to security concerns, although limited hunts were conducted late that season. Thus, females received almost complete protection for 2 years. Consequently, the population model estimated the 2002 prehunt population size at nearly twice that in 2000 and indicated that the population had surpassed its highest level since 1965 (Fig. 2). Female harvest was reinstated and hunter effort was increased, with harvest expectations corresponding to the increased population size. Harvest did increase (Fig. 2), although not as much as expected, being only slightly greater than the long-term average. Despite increased harvest, the model predicted that the population continued to grow; the 2002 harvest apparently had not been sufficient to control population growth. Again, a record harvest was expected in 2003, but in that year, harvest actually was lower than in 2002, again despite comparable hunter effort.

Although many factors affect deer harvest, divergence of the population estimate and annual harvest was puzzling, particularly given the history of their close relationship at SRS. In addition, hunters and biologists in the field reported that, rather than seeing high numbers of deer, observers were seeing few deer. The deer population estimate from the Novak et al. (1991) model appeared too high.

Annual deer spotlight surveys demonstrated that, beginning in the early 2000s, model estimates were no longer appropriate. From 1991 to 2002, spotlight counts corroborated model estimates, with both indicating a declining trend from 1991 to 2000 and an increasing trend from 2000 to 2002 (Fig. 2). However, the spotlight index and model estimate diverged in 2003. From that year through 2005, model estimates continued to climb, while spotlight indices continued to decline (Fig. 2).

Supporting the contention that spotlight counts more accurately reflected the actual trend in the population, annual harvest has remained low during the period of declining spotlight counts, reaching a low in 2005 at only $19 \%$ (214 of 1,136 deer) of the long-term mean annual harvest (1965-1999). With the low harvest that occurred from 2000 to 2004, the model predicted that the 2005 prehunt population (the last $\mathrm{yr}$ for which a prediction was available) should have approached 11,000 deer, or nearly twice the highest number in the population since 1965, and with the continued low harvest from 2005 to 2007, the 2008 prehunt population should have been far greater still. Yet, spotlight indices indicated that the population remained low. The low harvest initially (2003-2004) was due to depressed hunter success (i.e., effort remained constant) and subsequently (2005-2007) to reduced hunting effort (decreased intentionally in response to the perceived low population density). However, regardless of the cause, it was not possible for the population to remain at such low harvest and population size (as indexed by spotlight counts) without a substantial decrease in productivity or increase in nonharvest mortality. We know of no reason that productivity may have experienced a long-term decline. From 1965 to 1985 , mean reproductive rate at SRS among females $\geq 1.5$ years old was 1.66 fawns/female (Rhodes et al. 1985). During 2005 at SRS, mean number of fawns/female among 33 females $\geq 1.5$ years old averaged 1.70 (H. S. Ray, United States Forest Service, unpublished data).

In addition to hunter harvest, important mortality factors in some deer populations include disease, miscellaneous accidents, malnutrition, and predation (Halls 1984). Although hemorrhagic disease causes some mortality in deer populations in the Southeast during most years, reports of deer carcasses received by the South Carolina Department of Natural Resources during the past decade did not indicate an unusual level of disease-induced mortality in the state. Similarly, the number of deer-vehicle collisions during that period at SRS remained within long-term norms (P. Johns, University of Georgia Savannah River Ecology Laboratory, unpublished data). We know of no reason that mortality due to starvation should have increased, particularly in light of the low density of deer relative to similar areas in the region. Little is known about levels of predation in the population, but among 17 adult females radiomonitored over a 2-year period (2001-2002), 2 were killed by hunters, 1 was killed by vehicle collision, and 2 died of unknown causes (Comer 2005). Thus total mortality among adults does not appear high.

A recruitment index (fawn:ad $\mathrm{F}$ ratio) derived from harvest data may be a useful index to fawn survival at SRS because harvest bias against certain age classes and sexes is limited. Hunters were encouraged to shoot any deer regardless of sex or age and in most years there was no limit. Although some limits have been imposed in recent years (2000-present), potentially introducing some bias, we believe that the historic data can still serve as a useful index. 


\section{DE- AI09-00SR22188 Journal Article $2010 \quad$ 10-08-P}

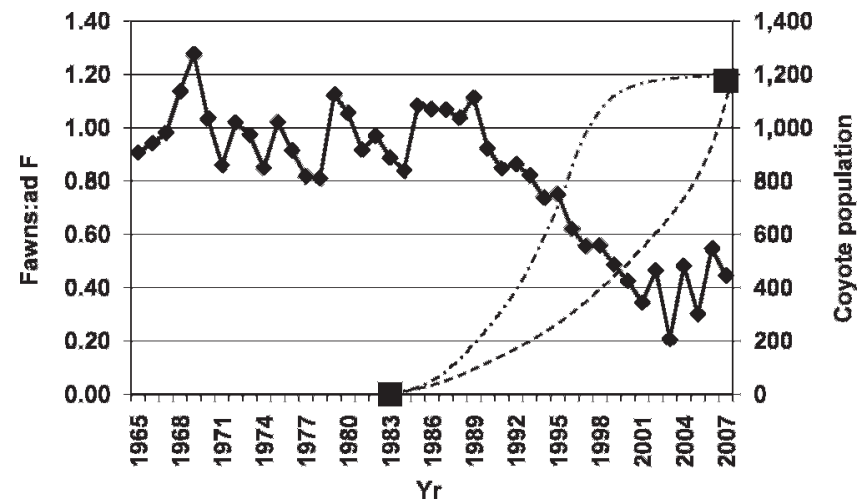

Figure 3. Number of fawns:adult female ( $\geq 2.5 \mathrm{yr}$ old) in harvest and estimated population size of coyotes at the Savannah River Site, South Carolina, USA, 1965-2007 (H. S. Ray, United States Department of Agriculture Forest Service, unpublished data). Dotted lines depicting coyote population growth indicate potential but unknown shapes of the population growth curve between the first record of coyotes and the present established population.

The ratio of fawns:adult female in the harvest suggests that fawn survival has declined in recent years. From 1965 to 1990, the number of fawns:adult female ranged from 0.81 to 1.27 (Fig. 3). However, during the early to mid-1990s, this figure began a precipitous decline that apparently leveled off during the late 1990s to early 2000s; from 1999 to 2006, the number of fawns:adult female ranged from 0.21 to 0.55 . This time frame, from 1999 to 2006, coincides roughly with the period when estimates from the population model and spotlight data diverged.

Could coyotes be the unknown new source of mortality to fawns in the population? The first record of a coyote on SRS was in 1986 and the population soon began to increase. Although data are not available on the population trend or the shape of its growth curve (Fig. 3), by the mid- to late 1990s sightings were common and coyotes could frequently be heard howling at night. In 2005, a population survey estimated density at 1.5 coyotes $/ \mathrm{km}^{2}$ (total population of 1,177; Schrecengost 2007), considerably higher than the average reported from Texas $\left(0.2-0.4\right.$ coyotes $\left./ \mathrm{km}^{2}\right)$ but lower than the maximum for favorable range there (2.0-2.4 coyotes $/ \mathrm{km}^{2}$; Knowlton 1972). Although Schrecengost (2007) acknowledged uncertainty in this estimate, its accuracy is not important in the present context. Rather, the important point is that the coyote population grew from zero in the early to mid-1980s to being well-established by 2000 , and this growth was concurrent with the decline in deer fawn recruitment.

Evidence from a coyote food habits study (Schrecengost et al. 2008) provides a direct link between coyotes and deer fawn mortality. During May (the peak of the fawning season at SRS) 2005 and 2006, 31\% and 38\%, respectively, of coyote scats contained deer fawn remains. Percentages for these 2 years in June were $15 \%$ and $23 \%$, respectively, and fawn remains were detected through August, although at lower frequencies. Based on these findings, Schrecengost et al. (2008) suggested that coyote-induced deer fawn mortality may be significant.
Other Southeastern Data

Two recent studies conducted in Alabama indicate the potential for predation by coyotes to impact deer populations there. Vangilder (2008) used camera surveys to assess fawn:adult female ratios before and after an experimental predator (coyote and bobcat [Lynx rufus]) removal. Prior to predator removal, the fawn:adult female ratio was 0.41 . The following year, after the removal of 22 coyotes and 10 bobcats during late winter, the fawn:adult female ratio was 1.20. Similarly, Saalfeld and Ditchkoff (2007) reported 67\% fawn mortality in an exurban deer population in Auburn, Alabama, with coyotes being the leading cause, responsible for $42-63 \%$ of all mortality.

\section{MANAGMENT IMPLICATIONS}

Although these data do not conclusively demonstrate that coyotes affect deer populations in the Southeast, we believe that the collective weight of the evidence is strong and warrants further research attention. Deer populations in most of the eastern United States have historically been managed under the premise that harvest was the only important source of mortality. If deer recruitment is reduced due to coyote predation on fawns, several questions arise. Even in areas with overabundant deer, where an additional controlling force may be welcomed, management strategies may need to be altered. The following questions are intended to highlight information gaps to help guide research on the relationship between deer and coyotes in the Southeast.

What is the level of coyote-induced mortality and is it additive? To adequately understand the dynamics of hunted deer populations, managers will need to know the answer to this question. Bartmann et al. (1992) reported that coyote predation of mule deer (O. hemionus) fawns was compensatory to other mortality sources, particularly malnutrition during winter. In the Southeast, winters are not severe and food resources are abundant, so coyote predation may be an additive mortality source. If coyote-induced mortality to fawns is additive, fawn loss must be considered to minimize the risk of overharvest.

How do either coyote density or deer density affect predation level? High-density deer populations may be able to avoid substantial levels of predation through predator swamping. A synchronous fawning period may overwhelm the ability of coyotes to have a major impact. Deer populations are most vulnerable when their density is low (Patterson et al. 2002) and coyote density is high, but the nature of this relationship is speculative.

How does vegetation structure affect predation level? Some have suggested that land managers can ameliorate predation on fawns by providing adequate fawning cover (Thomas 2005). However, habitat use by fawns is poorly understood in the densely vegetated Southeast and little to no information exists from the region on whether fawns that use dense cover are any more likely to survive than those that do not have it available. At what scale should cover be considered and what landscape structure might be beneficial to fawn survival? In addition, can habitat manipulation that improves availability of alternative prey, such as soft mast and small mammals, reduce coyote-induced fawn mortality? 


\section{DE- AI09-00SR22188 Journal Article $2010 \quad$ 10-08-P}

Is predation pressure uniform from year to year? In the Southwest, fawn predation is related to rainfall, with higher mortality in years of low rainfall when cover is limited and other coyote food sources are low (Beasom 1974). Does this relationship exist in the more humid climate of the Southeast? Fruit was the only food item in the coyote diet more important than fawns during the fawning season (Schrecengost et al. 2008). Does predation on fawns increase when the mast crop is poor?

Coyote food-habits studies throughout the East (Hall 1979, Wooding 1984, Blanton and Hill 1989, Samson and Crete 1997, Schrecengost et al. 2008) have indicated that coyotes frequently prey on fawns, just as coyotes do in their historic western range. The data we presented suggest that this predation may affect deer population dynamics in some areas. With coyote populations well-established throughout the East, research designed toward better understanding their potential impacts on deer is prudent.

\section{ACKNOWLEDGMENTS}

We thank the Savannah River Ecology Laboratory and United States Department of Agriculture (USDA) Forest Service-Savannah River for maintenance of and access to long-term deer harvest data. P. E. Johns and J. M. Novak were instrumental in compilation and management of this data through the 1990s and in providing insights into its strengths and limitations. We thank P. E. Johns and M. A. Vukovich for reviewing the manuscript. Funding was provided by the United States Department of EnergySavannah River Operations Office through the USDA Forest Service-Savannah River under Interagency Agreement DE-AI09-00SR22188 and by the USDA Forest Service Southern Research Station.

\section{LITERATURE CITED}

Ballard, W. B., D. Lutz, T. W. Keegan, L. H. Carpenter, and J. C. deVos, Jr. 2001. Deer predator relationships: a review of recent North American studies with emphasis on mule and black-tailed deer. Wildlife Society Bulletin 29:99-115.

Ballard, W. B., H. A. Whitlaw, S. J. Young, R. A. Jenkins, and G. J. Forbes. 1999. Predation and survival of white-tailed deer fawns in northcentral New Brunswick. Journal of Wildlife Management 63:574579 .

Bartmann, R. M., G. C. White, and L. H. Carpenter. 1992. Compensatory mortality in a Colorado mule deer population. Wildlife Monographs 121.

Bartush, W. S., and J. C. Lewis. 1981. Mortality of white-tailed deer fawns in the Wichita Mountains. Proceedings of the Oklahoma Academy of Science 61:23-27.

Beasom, S. L. 1974. Intensive short-term predator removal as a game management tool. Transactions of the North American Wildlife Conference 39:230-240.

Bishop, C. J., G. C. White, D. J. Freddy, B. E. Watkins, and T. R. Stephenson. 2009. Effect of enhanced nutrition on mule deer population rate of change. Wildlife Monographs 172.

Blanton, K. M., and E. P. Hill. 1989. Coyote use of white-tailed deer fawns in relation to deer density. Proceedings of the Annual Conference of the Southeastern Association of Fish and Wildlife Agencies 43:470-478.

Comer, C. E. 2005. An analysis of spatial and genetic population structure in white-tailed deer with implications for management. Dissertation, University of Georgia, Athens, USA.

Cook, R. S., M. White, D. O. Trainer, and W. C. Glazener. 1971. Mortality of young white-tailed deer fawns in south Texas. Journal of Wildlife Management 35:47-56.
Gompper, M. E. 2002. Top carnivores in the suburbs? Ecological and conservation issues raised by colonization of north-eastern North America by coyotes. Bioscience 52:185-190.

Hall, D. I. 1979. An ecological study of the coyote-like canid in Louisiana. Thesis, Louisiana State University, Baton Rouge, USA.

Halls, L. K. 1984. White-tailed deer: ecology and management. Stackpole, Harrisburg, Pennsylvania, USA.

Hill, E. P., P. W. Sumner, and J. B. Wooding. 1987. Human influences on range expansion of coyotes in the Southeast. Wildlife Society Bulletin 15:521-524.

Hilton, H. 1978. Systematics and ecology of the eastern coyote. Pages 209228 in M. Bekoff, editor. Coyotes: biology, behavior, and management. The Blackburn Press, Caldwell, New Jersey, USA.

Houben, J. M. 2004. Status and management of coyote depredations in the eastern United States. Sheep and Goat Research Journal 19:16-22.

Johns, P. E., and J. C. Kilgo. 2005. White-tailed deer. Pages 380-389 in J. C. Kilgo and J. I. Blake, editors. Ecology and management of a forest landscape: fifty years on the Savannah River Site. Island Press, Washington, D.C., USA.

Knowlton, F. K. 1972. Preliminary interpretations of coyote population mechanics with some management implications. Journal of Wildlife Management 36:369-382.

Lovell, C. D., B. D. Leopold, and C. C. Shropshire. 1998. Trends in Mississippi predator populations, 1980-1995. Wildlife Society Bulletin 26:552-556.

Main, M. B., S. F. Coates, and G. M. Allen. 2000. Coyote distribution in Florida extends southward. Florida Field Naturalist 28:201-203.

Messier, F., C. Barrette, and J. Huot. 1986. Coyote predation on a whitetailed deer population in southern Quebec. Canadian Journal of Zoology 64:1134-1136.

Novak, J. M., K. T. Scribner, W. D. DuPont, and M. H. Smith. 1991. Catch-effort estimation of white-tailed deer population size. Journal of Wildlife Management 55:31-38.

Nowak, R. M. 1978. Evolution and taxonomy of coyotes and related Canis. Pages 3-16 in M. Bekoff, editor. Coyotes: biology, behavior, and management. The Blackburn Press, Caldwell, New Jersey, USA.

Patterson, B. R., B. A. MacDonald, B. A. Lock, D. G. Anderson, and L. K. Benjamin. 2002. Proximate factors limiting population growth of whitetailed deer in Nova Scotia. Journal of Wildlife Management 66:511-521.

Rhodes, O. E., Jr., K. T. Scribner, M. H. Smith, and P. E. Johns. 1985. Factors affecting the number of fetuses in a white-tailed deer herd. Proceedings of the Annual Conference of the Southeastern Association of Fish and Wildlife Agencies 39:380-388.

Ruth, C. R. 2008. 2007. South Carolina deer harvest report. South Carolina Department of Natural Resources, Columbia, USA.

Saalfeld, S. T., and S. S. Ditchkoff. 2007. Survival of neonatal white-tailed deer in an exurban population. Journal of Wildlife Management 71:940944.

Samson, C., and M. Crete. 1997. Summer food habits and population density of coyotes, Canis latrans, in boreal forests of southeastern Quebec. Canadian Field Naturalist 11:227-233.

Schrecengost, J. D. 2007. Home range and food habits of the coyote (Canis latrans) at the Savannah River Site, South Carolina. Thesis, University of Georgia, Athens, USA.

Schrecengost, J. D., J. C. Kilgo, D. Mallard, H. S. Ray, and K. V. Miller. 2008. Seasonal food habits of the coyote in the South Carolina coastal plain. Southeastern Naturalist 7:135-144.

Thomas, L., Jr. 2005. QDM and coyotes. Quality Whitetails 12(5):12-18.

Vangilder, C. L. 2008. Coyote and bobcat food habits and the effects of an intensive predator removal on white-tailed deer recruitment in northeastern Alabama. Thesis, University of Georgia, Athens, USA.

Vreeland, J. K., D. R. Diefenbach, and B. D. Wallingford. 2004. Survival rates, mortality causes, and habitats of Pennsylvania white-tailed deer fawns. Wildlife Society Bulletin 32:542-553.

Whittaker, D. G., and F. G. Lindzey. 1999. Effect of coyote predation on early fawn survival in sympatric deer species. Wildlife Society Bulletin 27:256-262.

Wooding, J. B. 1984. Coyote food habits and the spatial relationship of coyotes and foxes in Mississippi and Alabama. Thesis, Mississippi State University, Mississippi State, USA.

Associate Editor: Bowman 